OPEN ACCESS

Edited by:

Peter A. Hall,

University of Waterloo, Canada

Reviewed by:

Ayșe Ikinci Keleş,

Niğde Ömer Halisdemir University,

Turkey

lan James Martins, University of Western Australia,

Australia

${ }^{*}$ Correspondence:

Li Yang

yang_li@gzhu.edu.cn

Specialty section:

This article was submitted to

Health,

a section of the journal

Frontiers in Human Neuroscience

Received: 03 September 2020 Accepted: 24 November 2020

Published: 15 December 2020

Citation:

Tabassum S, Misrani A and Yang $L$ (2020) Exploiting Common Aspects of Obesity and Alzheimer's Disease. Front. Hum. Neurosci. 14:602360. doi: 10.3389/fnhum.2020.602360

\section{Exploiting Common Aspects of Obesity and Alzheimer's Disease}

\author{
Sidra Tabassum, Afzal Misrani and Li Yang* \\ Precise Genome Engineering Center, School of Life Sciences, Guangzhou University, Guangzhou, China
}

Alzheimer's disease (AD) is an example of age-related dementia, and there are still no known preventive or curative measures for this disease. Obesity and associated metabolic changes are widely accepted as risk factors of age-related cognitive decline. Insulin is the prime mediator of metabolic homeostasis, which is impaired in obesity, and this impairment potentiates amyloid- $\beta(A \beta)$ accumulation and the formation of neurofibrillary tangles (NFTs). Obesity is also linked with functional and morphological alterations in brain mitochondria leading to brain insulin resistance (IR) and memory deficits associated with $\mathrm{AD}$. Also, increased peripheral inflammation and oxidative stress due to obesity are the main drivers that increase an individual's susceptibility to cognitive deficits, thus doubling the risk of $A D$. This enhanced risk of $A D$ is alarming in the context of a rapidly increasing global incidence of obesity and overweight in the general population. In this review, we summarize the risk factors that link obesity with $A D$ and emphasize the point that the treatment and management of obesity may also provide a way to prevent $A D$.

Keywords: obesity, insulin resistance, neuroinflammation, Alzheimer's disease, mitochondrial dysfunction

\section{INTRODUCTION}

The population of the developed world is aging, and the incidence of age-related metabolic and neurodegenerative diseases is increasing. Alzheimer's disease (AD) is one of the most common age-associated neurodegenerative diseases; it is characterized by the accumulation of extracellular amyloid- $\beta$ (A $\beta$ ) plaques and intracellular neurofibrillary tangles (NFTs; Jack, 2020; Sun et al., 2020). Mutations in one or more of the genes that encode amyloid precursor protein (APP), presenilin 1 (PS1), or presenilin 2 (PS2) represent genetic risk factors for AD (Gaiteri et al., 2016) and are typically associated with early-onset $\mathrm{AD}$, but account for less than half of all cases. Conversely, late-onset $\mathrm{AD}$ is associated with environmental factors (more specifically, lifestyle; Hohman and Kaczorowski, 2020). Environmental risk factors that are associated with AD include vascular lesions, atherosclerosis, hypertension, glucose intolerance, insulin resistance (IR), hyperglycemia, hyperinsulinemia, appetite dysregulation, and obesity (Hayden, 2019). Despite these insights, there are still, after decades of research, no disease-modifying or preventive treatments available. Therefore, identifying modifiable risk factors and finding the mechanistic links with $\mathrm{AD}$ is of significant interest.

Obesity is currently one of the most widespread health threats to have reached epidemic proportions worldwide and is projected to reach 573 million cases by 2030 (World Health Organization, 2020). The excess fat (adipose) tissue that accumulates in the body due to a prolonged imbalance between calorie intake and expenditure can result in obesity 
(El-Mallah and Obeid, 2020). It has been reported that humans have elevated susceptibility to obesity and an increased risk of non-alcoholic fatty liver disease (NAFLD) and degenerative diseases compared to nonhuman primates (Martins, 2012). Aging-associated obesity causes decreased lean mass and increased risk of obesity-related diseases (Pugazhenthi et al., 2017). Moreover, the aging process may also link NAFLD, another chronic disease whose global epidemic is expected to reach between 20 and $40 \%$ by 2020 , to obesity and $\mathrm{AD}$ (Bellentani et al., 2010). Consumption of a high-fat diet (HFD) is the prime cause of obesity and leads to various pathological conditions, including poor mental health, sleep apnea, and cognitive problems (Uranga and Keller, 2019). Although studies emphasize that obesity could increase the risk of dementia (Whitmer et al., 2007; Tezapsidis et al., 2009), the evidence is mixed for obesity as a risk factor for AD.

The long-term effects of the obesity epidemic, coupled with an aging global population, are severe and burdensome. Because of the profound socio-economic impact of both $\mathrm{AD}$ and obesity, it is imperative to understand the mechanisms that could connect the two conditions. This review article aims to highlight the common factors linking obesity with $\mathrm{AD}$; currently, these include insulin signaling pathways, oxidative stress, appetite dysregulation, neuroinflammation, and mitochondrial dysfunction in the brain, as summarized in Figure 1.

\section{OBESITY AND PROGRESSION OF AD}

According to the amyloid cascade hypothesis, AD-associated neurodegeneration is triggered by APP processing through the amyloidogenic pathway (Ow and Dunstan, 2014). The production of $A \beta$ plaques is generally regarded as influencing neuronal activity by impairing synaptic function and inducing cell death (Hong et al., 2016). Concerning obesity and its

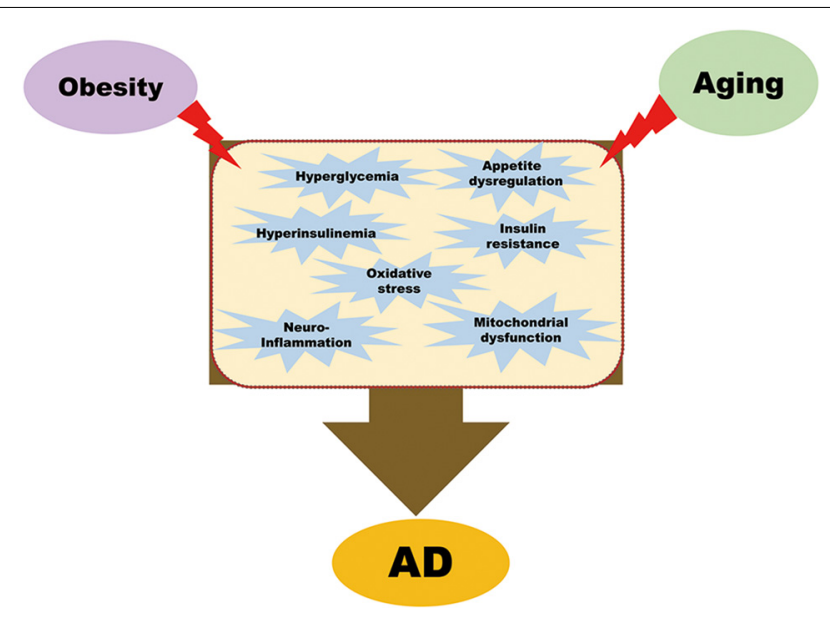

FIGURE 1 | Common pathological mechanisms that link obesity with Alzheimer's disease (AD). Obesity leads to hyperglycemia, hyperinsulinemia, insulin resistance, oxidative stress, appetite dysregulation, neuroinflammation, and mitochondrial dysfunction. All these pathological conditions, combined with aging, are contributory factors of $A D$. influence on $\mathrm{A} \beta$ deposition, several studies have reported body weight gain in APP transgenic mice in response to high-calorie diets. Diets vary from high-fat and high cholesterol diets to a diet rich in sucrose. Strangely, given the variation in the nutrient content of the various regimens, diet-induced obesity is consistently linked to a rise in cerebral $\mathrm{A} \beta$ pathology (LevinAllerhand et al., 2002; Fewlass et al., 2004; Ho et al., 2004; Cao et al., 2007; Pedrini et al., 2009; Julien et al., 2010; Shie et al., 2015). The only exception is a single study in which the authors examined the acute effects (i.e., after 4 weeks) of a "western" diet imposed on APP mice at 1-2 months of age (before A $\beta$ deposition; Studzinski et al., 2009). Similarly, a strong association between weight loss and decreased levels of cerebral $\mathrm{A} \beta$ plaques has been reported using several dietary regimens including ketogenic and calorie-restricted diets (Patel et al., 2005; Van der Auwera et al., 2005; Wang et al., 2005; Halagappa et al., 2007; Mouton et al., 2009) in different APP transgenic strains, providing evidence that body weight, diet, and obesity are important modulators of $A \beta$ pathology.

Another critical pathological feature of AD is NFTs, produced by hyperphosphorylated tau (Bartos et al., 2012). Multiple studies have demonstrated that tau pathology can be modulated by obesity (Leboucher et al., 2013; Platt et al., 2016). In a study to examine the dietary risk factors of AD, Julien et al. (2010) found that an HFD causes $A \beta$ and tau pathologies in the frontal cortex of the $3 \mathrm{xTg} \mathrm{AD}$ mouse model. The mitogenactivated protein kinase ( $\mathrm{p} 38, \mathrm{MAPK})$ signaling pathway is one of the major pathways disrupted in obesity (Katiyar and Meeran, 2007; Roth et al., 2009). This pathway is also linked with tau hyperphosphorylation and neuroinflammationmediated NFT generation (Kelleher et al., 2007), and the association is further confirmed by the observation of increased tau hyperphosphorylation in hyperinsulinemic rats (Freude et al., 2005). Moreover, HFD-induced obesity in the murine model results in $\mathrm{A} \beta$ plaques, NFTs, and inflammation in the hippocampus (Puig et al., 2012).

Collectively, these data suggest that obesity influences $\mathrm{A} \beta$ aggregation and tau phosphorylation, promoting the pathogenesis of AD. Since insulin is an important mediator of obesity-related pathologies, we will focus in the next section on brain insulin and how elevated insulin levels may relate to neurodegenerative disorders.

\section{BRAIN INSULIN SIGNALING AND AD}

Insulin mediates metabolic homeostasis by regulating glucose, lipids, and energy (Cheng et al., 2010b). The role of insulin in $\mathrm{AD}$ is currently of major interest (Arvanitakis et al., 2020; Selles et al., 2020). Insulin regulates glucose metabolism, both directly and indirectly. Insulin can be found in various brain areas under physiological conditions, especially in the cortex, hippocampus, and hypothalamus (Blazquez et al., 2014). The insulin levels in these brain regions are much higher than the insulin levels in plasma (Devaskar et al., 1994; Chiba et al., 2009; Kuwabara et al., 2011). Insulin is primarily derived from the blood and is transported to the brain via insulin binding sites present on brain endothelial cells (Hersom et al., 
2018). Insulin receptors are widely present in various brain areas, especially those regions that regulate olfaction, cognition, appetite, and autonomic activity (Marks et al., 1991; Pomytkin et al., 2018). Of the glucose transporters (GLUT), GLUT-4 is particularly important for cellular glucose uptake in most peripheral tissues and is mainly regulated by insulin (Mourelatou et al., 2019). However, insulin fails to induce cellular glucose uptake into neurons, nor are insulin receptors activated, since insulin does not influence the translocation of GLUT-4 in the brain (Talbot et al., 2012). Accordingly, other types of glucose transporter, for example, GLUT-3, mediate neuronal glucose uptake in an insulin-independent fashion (Nagamatsu et al., 1994). Several studies have consistently shown that insulin is linked to cognitive functions in the brain rather than neuronal glucose uptake like in peripheral organs (Plum et al., 2005; Cholerton et al., 2013).

Increasing evidence indicates that insulin affects the brain in numerous ways: it exerts neuroprotective effects, works as a neuromodulator, and also plays a role in memory and cognition (Nampoothiri et al., 2017; Pitt et al., 2017). Various studies have shown that either peripheral or central insulin administration has beneficial effects on learning and memory (Lee et al., 2016; Pearson-Leary et al., 2018), which have been linked to insulin receptor activation and downstream signaling (Nelson et al., 2008; Lin et al., 2010; Chambers et al., 2015). Insulin receptor beta-subunit haploinsufficiency affects hippocampal late-phase long-term potentiation (LTP) and memory processing (Nistico et al., 2012), and also makes long-term depression (LTD) more likely (Huang et al., 2003; Ahmadian et al., 2004). In synaptic areas, insulin might also modulate the release of neurotransmitters, particularly glutamate, which is crucial for the maintenance of synaptic transmission (Ahmadian et al., 2004). In summary, these findings indicate that insulin plays an essential role in neuromodulation, neuroprotection, and cognition.

As intimated earlier, insulin can cross the blood-brain barrier (BBB) and competes with $\mathrm{A} \beta$ for the insulin-degrading enzyme (IDE) in the brain, including in the hippocampus (Farris et al., 2003). Besides, insulin is also produced in the brain, which may have a favorable effect on amyloid clearance (Reger et al., 2006). Hence, impaired or elevated levels of insulin could have detrimental effects on the brain. For example, impaired insulin signaling could increase, at least in part, $A \beta$ accumulation and phosphorylation and cleavage of tau. As mentioned above, obesity is also a key contributor to metabolic dysfunction involving impaired insulin signaling, which leads to dysfunctional glucose metabolism. Hence, obesity-induced dysfunctional glucose metabolism might be the first common mechanism with relevance to $\mathrm{AD}$.

\section{GLUCOSE METABOLISM IN OBESITY AND AD}

Glucose metabolism and insulin signaling are essential for the proper functioning of the brain. Increasing evidence suggests that hypometabolism of glucose might be a key player in dementia pathology (Kuehn, 2020). Remarkably, changes in glucose metabolism are also associated with $\mathrm{AD}$ since imaging studies typically show decreased glucose metabolism in the temporal and parietal brain regions of $\mathrm{AD}$ patients and individuals at risk of developing this disease (Small et al., 2000). Besides, patients with $\mathrm{AD}$ may also have elevated fasting plasma insulin levels, attenuated insulin and insulin-like growth factor (IGF) receptor expression, and reduced cerebrospinal fluid (CSF)-toplasma insulin ratio relative to healthy individuals (Steen et al., 2005). Moreover, intravenous administration of insulin (while maintaining blood glucose levels) or glucose in $\mathrm{AD}$ patients and healthy older adults, improves cognitive function (Watson and Craft, 2004). These findings indicate that proper glucose metabolism is necessary for optimal cognitive function and that impairment of glucose metabolism leading to cognitive dysfunction is one of the characteristic features of $\mathrm{AD}$.

\section{Insulin Resistance (IR)}

IR is a pathological condition, often referred to as glucose intolerance, in which target tissues are not physiologically responsive to insulin. This may result in hyperinsulinemia occurring with euglycemia (Kim and Reaven, 2008). Hyperinsulinemia can interrupt the physiological function of several vital organs by impairing insulin signaling and disrupting intracellular signaling transduction (Zhang et al., 2007). Obesity is the major contributor to the induction of peripheral IR (Bacha et al., 2006; Jones et al., 2016; Fealy et al., 2018; Gao et al., 2019), resulting in overproduction of free fatty acids (FFAs) and causing oxidative stress (Tripathy et al., 2003). In rodents, chronic HFD-induced obese-IR exhibited a cognitive decline with impaired insulin regulation, increased inflammation, mitochondrial dysfunction, increased oxidative stress, and apoptosis in the brain (Porter et al., 2012; Sripetchwandee et al., 2014). These results suggest that chronic peripheral IR can induce brain IR and brain dysfunction.

IR also has relevance to $\mathrm{AD}$ because the metabolism of $A \beta$ is mechanistically linked to IR. As we described earlier, insulin is important for amyloid clearance, while IR reduces the clearance of $\mathrm{A} \beta$ and facilitates its aggregation via sequestration of IDE (a key enzyme for $\mathrm{A} \beta$ degradation; Qiu and Folstein, 2006). Insulin also affects the production and removal of $\mathrm{A} \beta$ through the MAPK signaling pathway. In brief, hyperinsulinemia or IR induces MAPK signaling pathway activation and increases BACE1 expression, which eventually triggers the excessive accumulation of $A \beta$ peptides and neuritic plaques. By contrast, IR inhibits the non-amyloidogenic pathway by reducing the expression of alpha-secretase and decreasing non-A $\beta$ peptide production (Gasparini et al., 2001). Increased $A \beta$ levels potentiate the removal of insulin receptors on the cell surface and further promote IR (De Felice et al., 2009). Although disrupted MAPK signaling is linked to the elevation of $A \beta$ levels, it also results in the generation of NFTs facilitated by tau hyperphosphorylation and neuroinflammation by activating extracellular signal-related kinase (ERK) or direct phosphorylation of transcription factor such as cyclic AMP response element (CRE)-binding protein (CREB; Kelleher et al., 2007; Hu et al., 2012). Furthermore, IR causes decreased phosphoinositide 3-kinase (PI3K)/AKT pathway activation and 
facilitates activation of glycogen synthase kinase (GSK) $3 \beta$ (one of the kinases involved in tau phosphorylation). Hence, increased GSK3 $\beta$ activation might cause hyperphosphorylation of tau and neurofibrillary lesions (Jolivalt et al., 2008). Additionally, IR blocks protein phosphatase 2A (PP2A) inhibition, which also leads to tau hyperphosphorylation and accumulation of NFTs (Gratuze et al., 2017).

These studies demonstrate that obesity-induced IR and hyperinsulinemia cause brain dysfunction and facilitate NFT and $A \beta$ accumulation, as summarized in Figure 2. Thus, obesity-induced IR or hyperinsulinemia represent a potential mechanistic link between obesity and AD.

\section{Advanced Glycation End Products (AGEs)}

Advanced glycation end products (AGEs) are harmful compounds in the bloodstream when protein or fat combines with sugar during the glycation cycle (Yamagishi and Matsui, 2010). RAGEs are receptors of AGEs that seem to play a significant role in response to an HFD, both in terms of body mass regulation, macrophage content of adipose tissue, and systemic metabolism (Tomino et al., 2011; Leuner et al., 2012). Elevated AGE levels in both serum and tissues occur in an animal model of obesity (Li et al., 2005). The literature links AGEs to obesity via oxidative stress and inflammatory processes (Ramasamy et al., 2005). Nevertheless, it is not clear to what degree high levels of circulating AGEs are the cause or a symptom of obesity or how AGEs and RAGEs can be affected by body fat and lifestyle factors. Though, mechanistic insights into how AGEs cause oxidative damage indicate that this happens through RAGEs, which are expressed on a variety of cells, including endothelial cells, smooth muscle cells, fibroblasts, and neurons (Kalousova et al., 2005). Once an AGE binds a RAGE molecule, various signal transduction pathways, such as those involving NF- $\kappa \beta$ or the MAPKs ERK and $c$-jun
$\mathrm{N}$-terminal kinase (JNK), can be activated. Consequently, gene transcription can be stimulated to increase the production of adhesion molecules, i.e., intercellular adhesion molecule-1 (ICAM-1), vascular cell adhesion molecule (VCAM-1) and growth factors like interleukin 1 (IL-1), IGF-1 and tumor necrosis factor $(\mathrm{TNF}-\alpha)$. Moreover, it is also suggested that glycation can occur in DNA: AGE modification of DNA may thus have an effect on epigenetic regulation and other regulatory processes at the genetic level (Ramasamy et al., 2005). A low-AGE diet attenuates inflammatory profiles in humans (Harcourt et al., 2011), and an AGE inhibitor reduces glucose intolerance, hyperinsulinemia, loss of body weight, and fat deposition (Hagiwara et al., 2009). Earlier research focused on the effects of AGEs on visceral adipose tissue, but we suggest that ongoing and future work should probe whether and to what degree AGEs and expression of RAGEs influence brain function.

AGE formation also leads to oxidative damage, which is often referred to as glycoxidation (Rabbani et al., 2016). Glycoxidation is extremely relevant to $\mathrm{AD}$, in part because extracellular fibrillar aggregates of $A \beta$ have AGE characteristics and bind to RAGEs in neurons and endothelial cells of the brain. Glycation can delay $\mathrm{A} \beta$ conversion to fibrils, maintaining them in toxic oligomeric forms for longer (Emendato et al., 2018). Simultaneously, A $\beta$ and AGE binding to RAGEs results in additional oxidative stress, which contributes to vascular dementia and neuronal death in AD (Takuma et al., 2009; Emendato et al., 2018; Wang et al., 2018). Furthermore, RAGEs mediate activation of GSK3 $\beta$, which increases tau phosphorylation and cognitive decline (Li et al., 2012). Collectively, the above studies lead us to speculate that AGEs play a significant role in AD pathogenesis. However, how obesity-induced increased AGEs or RAGEs affect brain function and how they interact with $\mathrm{AD}$ remains a missing link.

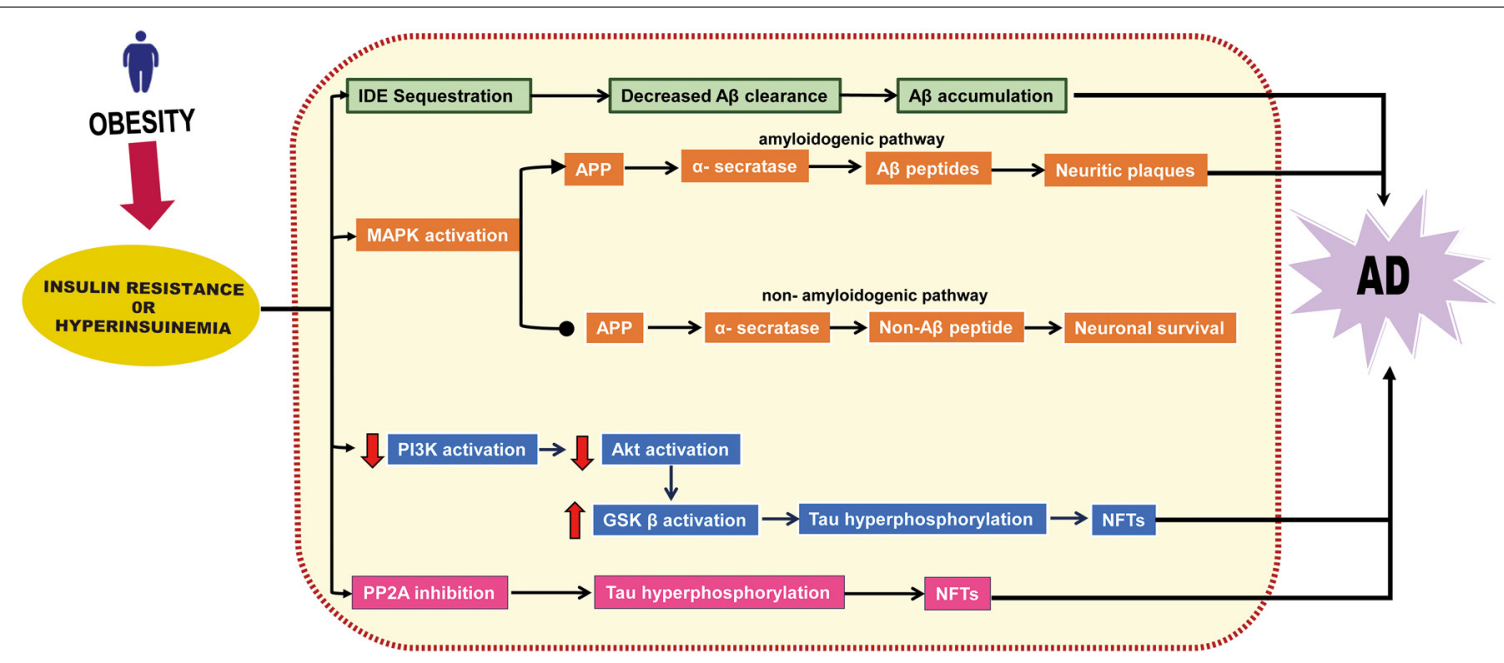

FIGURE 2 | Insulin resistance or hyperinsulinemia-related neurodegenerative pathway. Insulin resistance or hyperinsulinemia induces degradation of insulin-degrading enzyme (IDE), affects the MAPK signaling pathway, stimulates the amyloidogenic pathway, and inhibits the non-amyloidogenic pathway, thereby facilitating the accumulation of amyloid $\beta(A \beta)$. It also induces Akt downregulation that eventually boosts glycogen synthase kinase (GSK) $\beta$ activation and inhibits phosphatase 2A (PP2A) which leads to neurofibrillary tangles (NFTs) formation. 


\section{NEUROINFLAMMATION IN OBESITY AND AD}

Obesity is known to promote chronic low-grade systemic inflammation and neuroinflammation and is one of the most important mediators between obesity and $\mathrm{AD}$ (Gregor and Hotamisligil, 2011; Saltiel and Olefsky, 2017). Triglycerides (TGs), stored in the blood and adipose tissues, can be broken down into FFAs in individuals with obesity. FFAs initiate pro-inflammatory cytokine secretion from adipose tissue, which contributes to moderate and persistent systemic inflammation (Alford et al., 2018). Studies on obese and overweight adults showed altered levels of circulating inflammatory cytokines, including MCP-1, IL-6, IL-1 $\beta$, and TNF- $\alpha$, in these individuals (Chen et al., 2016). These altered levels of pro-inflammatory cytokines may establish an inflammatory milieu that reduces insulin sensitivity through feedback inhibition of the insulin receptor. This also disrupts mitochondrial function through a feed-forward mechanism, which then stimulates the production of reactive oxygen species (ROS) further to promote inflammation (Bonnard et al., 2008; Hoeks and Schrauwen, 2012). Such a chronic inflammatory milieu may stimulate NFK-B-inducing kinase activity, which independently promotes further IR by compromising mitochondrial function (Figure 3; Choudhary et al., 2011). These cytokines can cross the $\mathrm{BBB}$ and facilitate the extravasation of leukocytes from the circulation through the $\mathrm{BBB}$ into the central nervous system (CNS). Also, chronic inflammation causes damage to the $\mathrm{BBB}$ that can have deleterious effects on the CNS, including hypothalamic dysfunction, loss of synapses, impaired cognition, and neurodegeneration (Wyss-Coray and Mucke, 2002; Gregor and Hotamisligil, 2011; Bettcher and Kramer, 2013). The inflammation caused by obesity can, therefore, result in neuronal damage, usually beginning in adolescence.

While there is a minimal passage of FFAs across the BBB, positron emission tomography has demonstrated fatty acid uptake in the brain of obese individuals (Karmi et al., 2010). The presence of carnitine in various brain regions indicates that FFAs are involved in brain metabolism (Mitchell and Hatch, 2011). Nevertheless, toxic-level accumulation of fats in the brain can lead to damaging effects, such as inflammation of the brain. Long-chain fatty acids in the brain function via TLRs such as TLR4 and trigger cytokine production in local cells (microglia), eventually leading to activation of NF-кB signaling (Gupta et al., 2012). Hence, persistent CNS inflammation causes cerebral IR, hyperinsulinemia, and

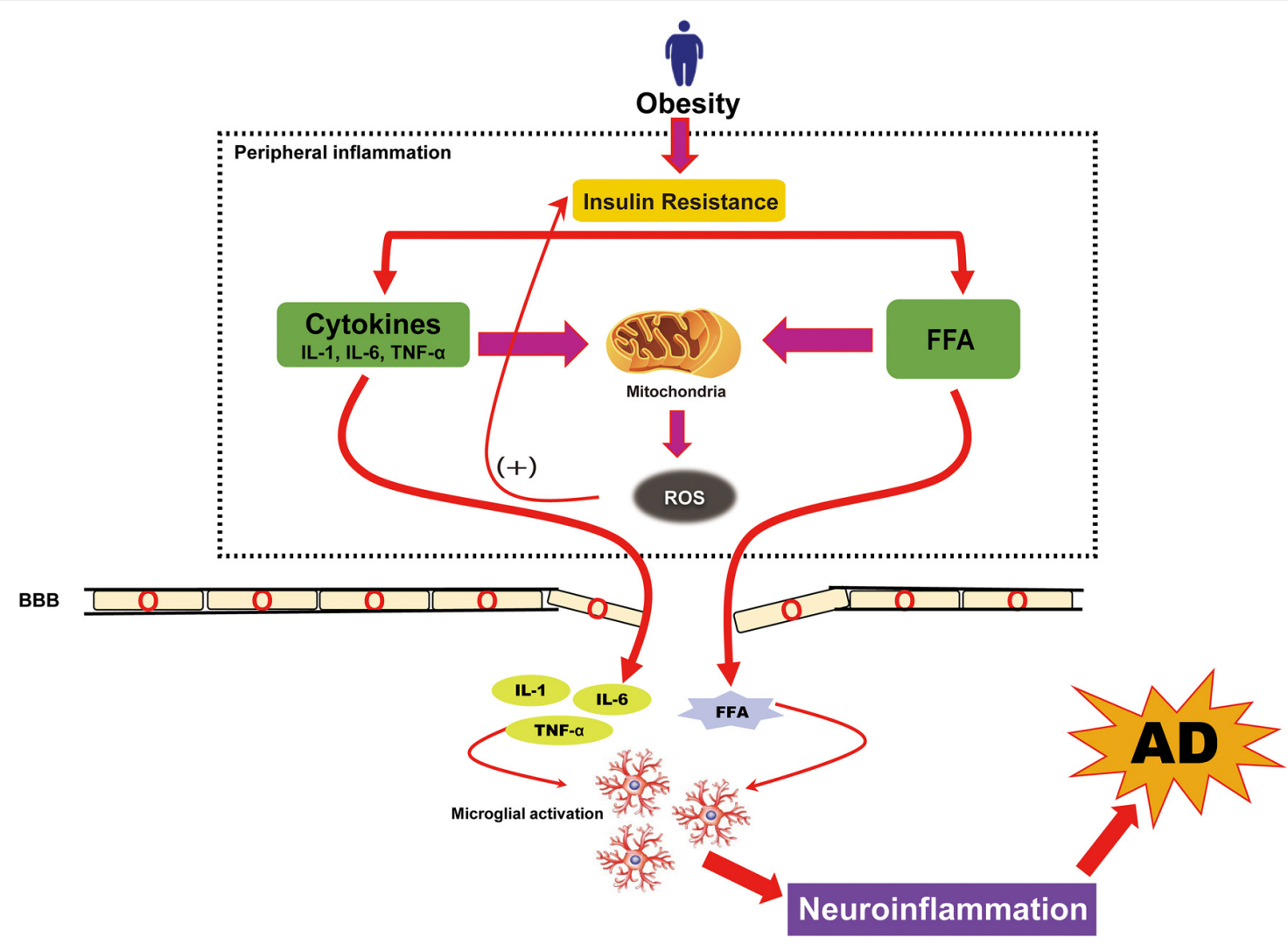

FIGURE 3 | Obesity-induced neuroinflammation in AD. Neuroinflammation caused by obesity is known to arise from low-grade, chronic peripheral inflammation. Obesity-induced insulin resistance causes an overload of free fatty acids (FFAs) and triggers the activation of peripheral cytokines that further increased reactive oxidative stress (ROS). Although peripheral cytokines and FFAs can cross the blood-brain barrier (BBB), their overload causes damage to the BBB. The presence of increased FFAs and cytokines in the brain follows the cytokine production in brain cells (microglia) and causes neuroinflammation. This neuroinflammation is also a pathologic hallmark of AD. 
hyperglycemia and consequently follow the production and deposition of AGE (Alford et al., 2018). Nevertheless, obesityinduced chronic low-grade inflammation in midlife provides a mechanistic association with a progressive cognitive decline as a result of CNS inflammation (Pugazhenthi et al., 2017).

Neuroinflammation is also considered a major contributor to $\mathrm{AD}$ pathogenesis. The pathological accumulation of $\mathrm{A} \beta$ alone may be sufficient to induce an inflammatory environment, which consequently contributes to progressive cognitive decline and $\mathrm{AD}$ (Guerriero et al., 2017). Considering the likelihood of $A \beta$ deposition preceding cognitive impairment or clinical manifestation, one might speculate that exogenous or endogenous factors may alter the innate immune response of microglia exposed to $A \beta$. We have summarized the molecular pathway in which environmentally modifiable $\mathrm{AD}$ risk factors such as obesity might affect $\mathrm{AD}$ pathogenesis through a sustained neuroinflammatory drive (Figure 3).

\section{MITOCHONDRIAL DYSFUNCTION IN OBESITY AND AD}

Mitochondria are usually referred to as the cellular powerhouses as they provide energy to the cell (Morrow et al., 2017; Bertolin et al., 2018). Mitochondrial dysfunction has been observed in both $\mathrm{AD}$ and obese individuals with insulin resistance (Vernochet and Kahn, 2012; Ji et al., 2015; Swerdlow, 2020). As well as adenosine triphosphate (ATP) production, mitochondria play numerous roles in neurons such as $\mathrm{Ca}^{2+}$ regulation, lipid metabolism, ROS signaling, and cell survival or death (Torralba et al., 2016; Pfanner et al., 2019). Regarding brain activity, studies have shown that mitochondria are important for cognitive function and synaptic transmission (Mattson et al., 2008; Cheng et al., 2010a; Raefsky and Mattson, 2017; Lee et al., 2018). Specifically, presynaptic mitochondria endorse sustained synaptic activity by providing ATP and buffering presynaptic $\mathrm{Ca}^{2+}$ signals, thereby modulating neurotransmission and eventually imposing an upper limit on synaptic activity. Also, mitochondrial morphological changes in presynaptic neurons impair synaptic homeostasis, and may, therefore, lead to neurodegeneration (Devine and Kittler, 2018). Morphologically, donut-shaped mitochondria are indicative of mitochondrial stress (Liu and Hajnoczky, 2011; Ahmad et al., 2013) and correlate with the deterioration of working memory with aging (Hara et al., 2014). In subsequent studies, the authors found that donut mitochondria are linked with reduced synapse formation, as demonstrated by smaller active zone sizes. Moreover, donut-containing presynaptic terminals have fewer fully docked vesicles, which indicates a reduced potential for the release of synaptic vesicles containing neurotransmitters. Hence brain mitochondria, and more specifically, presynaptic mitochondria, significantly affect cognitive function (Dragicevic et al., 2010; Baek et al., 2017), which supports the hypothesis that mitochondrial dysfunction may result in cognitive impairment. Similarly, mitochondrial $A \beta$ accumulation and mitochondrial dysfunction were observed in an $\mathrm{AD}$ mouse model, and the degree of these impairments correlated with the extent of cognitive decline (Dragicevic et al., 2010).
Brain mitochondrial dysfunction is also linked with an obese/insulin-resistant condition (Hunnicut et al., 2015; Koliaki and Roden, 2016; Thoudam et al., 2019). Both an HFD and genetically mediated obesity/IR consistently cause mitochondrial dysfunction characterized by alterations in mitochondrial membrane potential, excessive mitochondrial ROS production, and swollen mitochondria with unfolded cristae (Ciapaite et al., 2007; Cardoso et al., 2010; Gomes et al., 2012; Guo et al., 2013; Kalinovich et al., 2016). A reduction in ATP levels as a consequence of mitochondrial dysfunction, i.e., reduced $\mathrm{O}_{2}$ consumption and excessive $\mathrm{CO}_{2}$ output, occurs in obese/IR rats (Porter et al., 2012, 2013; Raza et al., 2015; Wang et al., 2015). These studies only reported on the association between obesity/IR and dysfunction of brain mitochondria and brain IR (Pintana et al., 2013; Pipatpiboon et al., 2013; Sa-Nguanmoo et al., 2016, 2017), but to date, it is still unclear how peripheral mitochondrial dysfunction leads to brain IR and brain mitochondrial dysfunction.

Mitophagy, a type of autophagy, plays a significant role in maintaining a healthy mitochondrial pool and ensuring neuronal function and survival, and mitophagy deficits might be the leading pathological cause of $\mathrm{A} \beta$ enrichment (Wang et al., 2016). Pink-1-parkin and Sirtuin (Sirt) mediated mitophagy pathways are getting more focus with relevance to chronic diseases, including AD (Fang et al., 2016) and obesity (Ren et al., 2020). Sirt-1, a member of the deacetylase protein family exerting protective effects against cellular insult (Zhang et al., 2016), is involved in the regulation of a variety of cellular stress responses such as inflammation, autophagy, and apoptosis (programmed cell death; Hall et al., 2013). Some studies link brain apoptosis with mitochondrial dysfunction (Sa-Nguanmoo et al., 2016, 2017). One possible explanation is that, due to mitochondrial swelling, cytochrome $\mathrm{c}$ is released, resulting in the development of a complex with apoptotic protease activating factor-1 (APAF-1). These complexes become the apoptosomes and activate caspase cascades, which eventually trigger apoptosis (Cozzolino et al., 2006; Spellicy et al., 2018). In line with the above notions, it was found that mitochondrial dysfunction causes enhancement of pro-apoptotic protein (Bax and Bad) levels, and reduction in anti-apoptotic protein (Bcl-2) levels in the brain of obese/IR rats (Nuzzo et al., 2015; Sa-Nguanmoo et al., 2016, 2017). An increase in pro-apoptotic proteins can cause the release of cytochrome c, leading to apoptosis in the brain (GomezLazaro et al., 2007; Gomez-Crisostomo et al., 2013). Apoptosismediated neuronal death has also been observed in several neurodegenerative diseases and is considered a key process underlying cognitive dysfunction (Ghavami et al., 2014).

Besides the generation of energy and apoptosis, mitochondrial processes such as fission and fusion also support cell survival or death (Perfettini et al., 2005). Neurodegeneration and cognitive dysfunction are associated with an imbalance in mitochondrial dynamics as well as with brain mitochondrial dysfunction (Knott and Bossy-Wetzel, 2008; Bertholet et al., 2016). Previously, it was reported that the imbalance in mitochondrial dynamics implied by a reduction in mitochondrial fusion in conjunction with an increase in mitochondrial fission, leads to cognitive dysfunction and cell death (Cho et al., 2010). More specifically, 


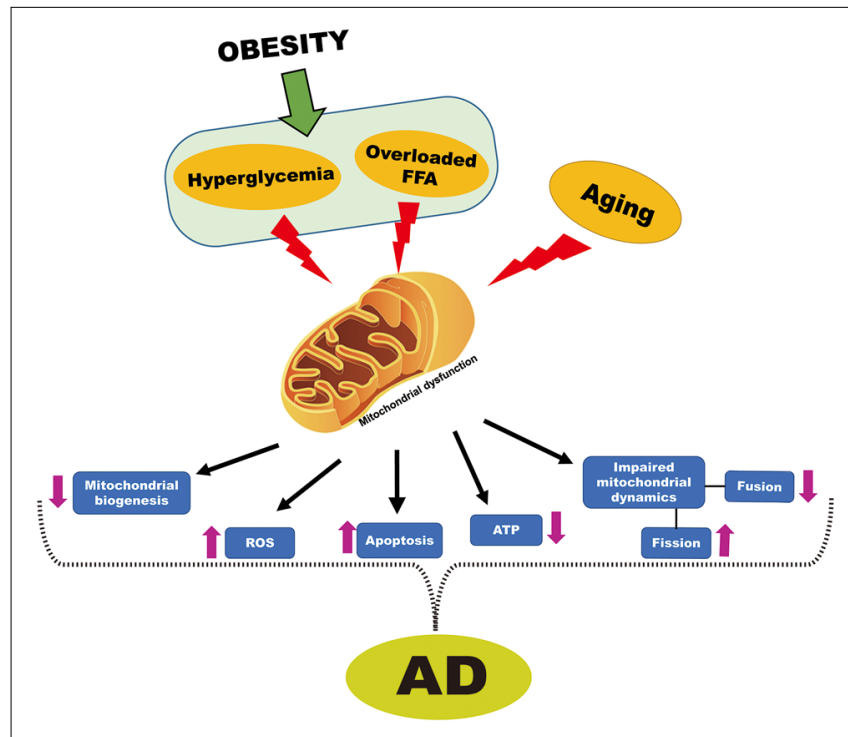

FIGURE 4 | Obesity-induced mitochondrial dysfunction cross-talk with AD. Hyperglycemia and overloaded FFA that are associated with obesity and aging are known to cause mitochondrial dysfunction. Dysfunctional mitochondria decreased mitochondrial biogenesis, increased ROS, increased apoptosis, reduced adenosine triphosphate (ATP) generation, impaired mitochondrial dynamics, which is characterized by increased fission and reduced fusion. All of these events are also associated with mitochondrial dysfunction in AD.

mitochondrial fission protein (Drp-1) is involved in synaptic dysfunction and neurodegeneration as Drp-1 inhibitor improved age-related synaptic depression, cognitive decline, and $\mathrm{A} \beta$ accumulation in APP/PS1 mice (Baek et al., 2017). Similarly, this imbalance in mitochondrial dynamics is also seen in obesity/IR, as shown by decreased expression of mitochondrial fusion proteins and increased expression of mitochondrial fission proteins (Diaz et al., 2015; Filippi et al., 2017). Hence the underlying mechanisms responsible for age-related cognitive decline or cognitive dysfunction in obesity/IR are likely either imbalanced mitochondrial dynamics or impaired brain mitochondrial function. Based on the above reports, there is strong evidence to suggest that obesity leads, at least in part, to the onset of $\mathrm{AD}$ by compromising mitochondrial function (Figure 4).

\section{APPETITE DYSREGULATION IN OBESITY AND AD}

Dietary/ appetite regulation of the nuclear receptors involves the Sirt-1 gene (also known as calorie sensitive anti-aging gene; Martins, 2016b), which has a close link with the development of $\mathrm{AD}$ (Pardo and Boriek, 2020). In global populations, the $\mathrm{AD}$-associated appetite dysregulation in early life shows defective suprachiasmatic nucleus (SCN) in the appetite center, hypothalamus (Reisberg et al., 1989; Nifli, 2018). Physiologically, Sirt 1 is involved in $A \beta$ clearance from neurons and inhibiting inflammatory responses in neuroglia, thus functions as a neuroprotective factor against $A \beta$ toxicity and cognitive deficits
(Li et al., 2018). Conversely, during the aging process, Sirt-1 activity is suppressed due to transcriptional dysregulation, leading to defective mitophagy and $\mathrm{AD}$ accelerations (Yuan et al., 2016). Additionally, Sirt-1 also plays a significant role in the glucose and fat homeostasis by regulating various transcription factors; reduction in Sirt-1 activity due to either HFD or unhealthy diet leads to insulin resistance (Chen et al., 2013), altered immunity, mitochondrial apoptosis, and NAFLD (Martins, 2017b). Moreover, Nitric oxide (NO) is one of the principal regulators of various mitochondrial functions such as mitochondrial biogenesis and mitochondrial respiration (Nisoli et al., 2003; Bombicino et al., 2017) and appetite regulation (Morley et al., 2011); whose disturbances are extensively reported in various chronic diseases, such as $\mathrm{AD}$ (Tse, 2017) and obesity (Rus et al., 2016). Existing literature reported that Sirt-1 prevents oxidative stress by maintaining NO levels and creating ROS resistance (Zhang et al., 2017). These reports, together, suggest that appetite dysregulation may be critically involved in obesity and $\mathrm{AD}$ pathogenesis.

\section{DISCUSSION AND CONCLUSION}

While the mechanisms underlying $\mathrm{AD}$ are not yet completely understood, it is evident that $\mathrm{AD}$ follows a series of critical events in the brain over time. There is convincing evidence that obesity is linked with $\mathrm{AD}$, especially in middle age and in younger adults. This association alone makes understanding the mechanisms and pitfalls addressed in this review essential. The connections between dementia, obesity, and aging represent a major threat to public health, particularly as people are adopting increasingly sedentary lifestyles. The preference is for a westernstyle diet with high levels of starch, fat, sugar, and oil, and this is coupled with reduced energy expenditure. This "double whammy" creates an imbalance between calorie intake and expenditure that collectively leads to obesity. Though the severity of obesity and its relevance to $\mathrm{AD}$ differs between developing and developed countries (Martins, 2013), the quality of food and xenobiotics levels might underlie this discrepancy (Martins, 2016a). A report on childhood obesity predicts that, by 2030, over 250 million young people will be classified as obese, from school-aged children to adolescents, thereby placing a massive burden on health care systems. While there have been numerous attempts to eliminate the causes and consequences of obesity, the management of blood glucose combined with weight loss seems to be, currently, the only successful strategy. However, the therapeutic interventions to prevent these interlinked diseases are still obscure.

Accordingly to the current literature, the most likely mechanisms linking obesity to $\mathrm{AD}$ involve IR, AGE accumulation, neuroinflammation, mitochondrial dysfunction, and appetite dysregulation. Though, oxidative stress and hyperglycemia contribute to $\mathrm{AD}$ pathogenesis as they potentiate $\mathrm{A} \beta$ deposition, hyperphosphorylation of tau, and eventually neuronal and synaptic failure. Hyperinsulinemia or IR, and their role in $\mathrm{AD}$ progression, have fostered tremendous interest recently and are thus topics of intensive research. However, it is still unclear whether these are just correlations or whether there 
is a direct effect on the amyloid cascade and $\mathrm{AD}$, and whether any intervention will modify the risk of disease. In our opinion, this is the most important question in the field.

As discussed earlier, obesity-associated inflammation facilitates $\mathrm{AD}$; hence neuroinflammation might be a critical pathway that accelerates the aging process, and its malfunction leads to alteration in other intersecting pathways related to obesity and $\mathrm{AD}$ as discussed in this review. Indeed, chronic neuroinflammation contributes to the development and progression of $\mathrm{AD}$, but whether peripheral inflammation triggers neuroinflammation in $\mathrm{AD}$ is not entirely clear. More work is therefore required to identify the origin of inflammation in $\mathrm{AD}$. Additionally, the role of TNF- $\alpha$ and NF-kB upregulation in neurons is extremely complex, and it is difficult to define any clear relationship with $\mathrm{AD}$ onset; further studies are therefore necessary for obese brain tissue. Although studies also correlate $\mathrm{AD}$ with mitochondrial dysfunction in obesity, how peripheral mitochondrial dysfunction causes dysfunctional brain mitochondria, and how this leads to $\mathrm{AD}$ is still unknown. We propose that the brain mitochondrial involvement in early pathogenesis should receive more emphasis on ongoing $\mathrm{AD}$ research programs. Based on what is understood about the natural history of obesity and our analysis of current evidence, we believe that obesity, when combined with aging, plays a significant role in $\mathrm{AD}$ pathogenesis.

One of the major risk factors of obesity is an unhealthy diet, which is involved in epigenetic modifications that further affect nuclear/mitochondria interactions and inactivate Sirt-1, thus accelerating NAFLD and obesity in the global population (Martins et al., 2015; Pardo and Boriek, 2020). Since repression of Sirt-1 is involved in obesity and $\mathrm{AD}$, proteomic profiles that include early plasma Sirt-1 detection could be used as a biomarker associating with the inactivation of rapid toxic $\mathrm{A} \beta$ and therapeutic drug metabolism (Martins, 2018). Hence, a diagnostic test that can detect Sirt-1 inactivation, will provide an early insight into later disease alterations. Furthermore, as early nutritional intervention causes activation of the Sirt-1 pathway that reverse NAFLD with reduced obesity and prevent mitochondrial apoptosis (Martins, 2017a);

\section{REFERENCES}

Ahmad, T., Aggarwal, K., Pattnaik, B., Mukherjee, S., Sethi, T., Tiwari, B. K., et al. (2013). Computational classification of mitochondrial shapes reflects stress and redox state. Cell Death Dis. 4:e461. doi: 10.1038/cddis.2012.213

Ahmadian, G., Ju, W., Liu, L., Wyszynski, M., Lee, S. H., Dunah, A. W., et al. (2004). Tyrosine phosphorylation of GluR2 is required for insulin-stimulated AMPA receptor endocytosis and LTD. EMBO J. 23, 1040-1050. doi: 10.1038/sj. emboj.7600126

Alford, S., Patel, D., Perakakis, N., and Mantzoros, C. S. (2018). Obesity as a risk factor for Alzheimer's disease: weighing the evidence. Obes. Rev. 19, 269-280. doi: 10.1111/obr.12629

Arvanitakis, Z., Wang, H. Y., Capuano, A. W., Khan, A., Taib, B., AnokyeDanso, F., et al. (2020). Brain insulin signaling, Alzheimer disease pathology and cognitive function. Ann. Neurol. doi: 10.1002/ana.25826. [Epub ahead of print].

Bacha, F., Saad, R., Gungor, N., and Arslanian, S. A. (2006). Are obesityrelated metabolic risk factors modulated by the degree of insulin resistance in adolescents? Diabetes Care 29, 1599-1604. doi: 10.2337/dc06-0581 therefore, pharmacological interventions which either prevent downregulation of Sirt-1 or upregulation of Sirt-1 would be beneficial for people with obesity and AD.

Obesity is contributing to glucose sensitivity and hyperinsulinemia/IR, which are known $\mathrm{AD}$ risk factors. IR is responsible for tau hyperphosphorylation and $A \beta$ aggregation via the various mechanisms discussed in this review, leading to the pathogenesis of $\mathrm{AD}$. All these factors can occur sequentially, but may also coexist. It is currently unknown how early lifelong obesity affects the risk of $\mathrm{AD}$, but given the impact of hyperinsulinemia on brain amyloid metabolism the onset of the conditions that underlie the disease could begin at a young age or even in childhood. Since there is an increasing trend of obesity among children and adults, this possibility is overwhelming. Thus, it will be important to use traditional measures of obesity such as BMI in younger persons, and to study the correlation of obesity and $\mathrm{AD}$, to attempt to clarify conflicting findings in the literature. Ethnicity and gender may also have differential effects on obesity, so we suggest taking ethnic group, age, and gender into consideration irrespective of the cut-offs for these measures. Additionally, it will be important to directly measure body composition in older adults to better understand the effects of obesity in this key subset of the population. Further research needs to determine how the prevention, treatment, and lifelong care of obesity might delay or reduce the risk of $\mathrm{AD}$.

\section{AUTHOR CONTRIBUTIONS}

ST and LY designed the theme of the manuscript. ST wrote most sections. AM wrote one section of the manuscript. All authors reviewed the manuscript before submission. All authors contributed to the article and approved the submitted version.

\section{FUNDING}

We want to thank the National Natural Science Foundation of China (31771219, 31871170, 31970915) and the Guangdong Natural Science Foundation for Major Cultivation Project (2018B030336001) for the support.

Baek, S. H., Park, S. J., Jeong, J. I., Kim, S. H., Han, J., Kyung, J. W., et al. (2017). Inhibition of Drp1 ameliorates synaptic depression, A $\beta$ deposition and cognitive impairment in an Alzheimer's disease model. J. Neurosci. 37, 5099-5110. doi: 10.1523/JNEUROSCI.2385-16.2017

Bartos, A., Fialova, L., Svarcova, J., and Ripova, D. (2012). Patients with Alzheimer disease have elevated intrathecal synthesis of antibodies against tau protein and heavy neurofilament. J. Neuroimmunol. 252, 100-105. doi: 10.1016/j.jneuroim. 2012.08.001

Bellentani, S., Scaglioni, F., Marino, M., and Bedogni, G. (2010). Epidemiology of non-alcoholic fatty liver disease. Dig. Dis. 28, 155-161. doi: 10.1159/0002 82080

Bertholet, A. M., Delerue, T., Millet, A. M., Moulis, M. F., David, C., Daloyau, M., et al. (2016). Mitochondrial fusion/fission dynamics in neurodegeneration and neuronal plasticity. Neurobiol. Dis. 90, 3-19. doi: 10.1016/j.nbd.2015. 10.011

Bertolin, G., Bulteau, A. L., Alves-Guerra, M. C., Burel, A., Lavault, M. T., Gavard, O., et al. (2018). Aurora kinase A localises to mitochondria to control organelle dynamics and energy production. eLife 7:e38111. doi: 10.7554/eLife. 38111 
Bettcher, B. M., and Kramer, J. H. (2013). Inflammation and clinical presentation in neurodegenerative disease: a volatile relationship. Neurocase 19, 182-200. doi: 10.1080/13554794.2011.654227

Blazquez, E., Velazquez, E., Hurtado-Carneiro, V., and Ruiz-Albusac, J. M. (2014). Insulin in the brain: its pathophysiological implications for States related with central insulin resistance, type 2 diabetes and Alzheimer's disease. Front. Endocrinol. 5:161. doi: 10.3389/fendo.2014.00161

Bombicino, S. S., Iglesias, D. E., Rukavina-Mikusic, I. A., Buchholz, B., Gelpi, R. J., Boveris, A., et al. (2017). Hydrogen peroxide, nitric oxide and ATP are molecules involved in cardiac mitochondrial biogenesis in diabetes. Free Radic. Biol. Med. 112, 267-276. doi: 10.1016/j.freeradbiomed.2017.07.027

Bonnard, C., Durand, A., Peyrol, S., Chanseaume, E., Chauvin, M. A., Morio, B., et al. (2008). Mitochondrial dysfunction results from oxidative stress in the skeletal muscle of diet-induced insulin-resistant mice. J Clin. Invest. 118, 789-800. doi: 10.1172/JCI32601

Cao, D., Lu, H., Lewis, T. L., and Li, L. (2007). Intake of sucrose-sweetened water induces insulin resistance and exacerbates memory deficits and amyloidosis in a transgenic mouse model of Alzheimer disease. J. Biol. Chem. 282, 36275-36282. doi: 10.1074/jbc.M703561200

Cardoso, A. R., Cabral-Costa, J. V., and Kowaltowski, A. J. (2010). Effects of a high fat diet on liver mitochondria: increased ATP-sensitive $\mathrm{K}+$ channel activity and reactive oxygen species generation. J. Bioenerg. Biomembr. 42, 245-253. doi: 10.1007/s10863-010-9284-9

Chambers, D. B., Androschuk, A., Rosenfelt, C., Langer, S., Harding, M., and Bolduc, F. V. (2015). Insulin signaling is acutely required for long-term memory in Drosophila. Front. Neural Circuits 9:8. doi: 10.3389/fncir.2015. 00008

Chen, S., Jiang, H., Wu, X., and Fang, J. (2016). Therapeutic effects of quercetin on inflammation, obesity and type 2 diabetes. Mediators Inflamm. 2016:9340637. doi: 10.1155/2016/9340637

Chen, Y. R., Lai, Y. L., Lin, S. D., Li, X. T., Fu, Y. C., and Xu, W. C. (2013). SIRT1 interacts with metabolic transcriptional factors in the pancreas of insulin-resistant and calorie-restricted rats. Mol. Biol. Rep. 40, 3373-3380. doi: 10.1007/s11033-012-2412-3

Cheng, A., Hou, Y., and Mattson, M. P. (2010a). Mitochondria and neuroplasticity. ASN Neuro 2:e00045. doi: 10.1042/AN20100019

Cheng, Z., Tseng, Y., and White, M. F. (2010b). Insulin signaling meets mitochondria in metabolism. Trends Endocrinol. Metab. 21, 589-598. doi: 10.1016/j.tem.2010.06.005

Chiba, T., Inoue, D., Mizuno, A., Komatsu, T., Fujita, S., Kubota, H., et al. (2009). Identification and characterization of an insulin receptor substrate 4 -interacting protein in rat brain: implications for longevity. Neurobiol. Aging 30, 474-482. doi: 10.1016/j.neurobiolaging.2007.07.008

Cho, D. H., Nakamura, T., and Lipton, S. A. (2010). Mitochondrial dynamics in cell death and neurodegeneration. Cell. Mol. Life Sci. 67, 3435-3447. doi: 10.1007/s00018-010-0435-2

Cholerton, B., Baker, L. D., and Craft, S. (2013). Insulin, cognition and dementia. Eur. J. Pharmacol. 719, 170-179. doi: 10.1016/j.ejphar.2013.08.008

Choudhary, S., Sinha, S., Zhao, Y., Banerjee, S., Sathyanarayana, P., Shahani, S., et al. (2011). NF-кB-inducing kinase (NIK) mediates skeletal muscle insulin resistance: blockade by adiponectin. Endocrinology 152, 3622-3627. doi: 10.1210/en.2011-1343

Ciapaite, J., Bakker, S. J., Van Eikenhorst, G., Wagner, M. J., Teerlink, T., Schalkwijk, C. G., et al. (2007). Functioning of oxidative phosphorylation in liver mitochondria of high-fat diet fed rats. Biochim. Biophys. Acta 1772, 307-316. doi: 10.1016/j.bbadis.2006.10.018

Cozzolino, M., Ferri, A., Ferraro, E., Rotilio, G., Cecconi, F., and Carri, M. T. (2006). Apaf1 mediates apoptosis and mitochondrial damage induced by mutant human SOD1s typical of familial amyotrophic lateral sclerosis. Neurobiol. Dis. 21, 69-79. doi: 10.1016/j.nbd.2005.06.010

De Felice, F. G., Vieira, M. N., Bomfim, T. R., Decker, H., Velasco, P. T., Lambert, M. P., et al. (2009). Protection of synapses against Alzheimer'slinked toxins: insulin signaling prevents the pathogenic binding of $\mathrm{A} \beta$ oligomers. Proc. Natl. Acad. Sci. U S A 106, 1971-1976. doi: 10.1073/pnas.08091 58106

Devaskar, S. U., Giddings, S. J., Rajakumar, P. A., Carnaghi, L. R., Menon, R. K., and Zahm, D. S. (1994). Insulin gene expression and insulin synthesis in mammalian neuronal cells. J. Biol. Chem. 269, 8445-8454.
Devine, M. J., and Kittler, J. T. (2018). Mitochondria at the neuronal presynapse in health and disease. Nat. Rev. Neurosci. 19, 63-80. doi: 10.1038/nrn.2017.170

Diaz, B., Fuentes-Mera, L., Tovar, A., Montiel, T., Massieu, L., MartinezRodriguez, H. G., et al. (2015). Saturated lipids decrease mitofusin 2 leading to endoplasmic reticulum stress activation and insulin resistance in hypothalamic cells. Brain Res. 1627, 80-89. doi: 10.1016/j.brainres.2015.09.014

Dragicevic, N., Mamcarz, M., Zhu, Y., Buzzeo, R., Tan, J., Arendash, G. W., et al. (2010). Mitochondrial amyloid- $\beta$ levels are associated with the extent of mitochondrial dysfunction in different brain regions and the degree of cognitive impairment in Alzheimer's transgenic mice. J. Alzheimers Dis. 20, S535-S550. doi: 10.3233/JAD-2010-100342

El-Mallah, C., and Obeid, O. (2020). Obesity and adiposity: the culprit of dietary protein efficacy. Clin. Sci. 134, 389-401. doi: 10.1042/CS20190583

Emendato, A., Milordini, G., Zacco, E., Sicorello, A., Dal Piaz, F., Guerrini, R., et al. (2018). Glycation affects fibril formation of A $\beta$ peptides. J. Biol. Chem. 293, 13100-13111. doi: 10.1074/jbc.RA118.002275

Fang, E. F., Scheibye-Knudsen, M., Chua, K. F., Mattson, M. P., Croteau, D. L., and Bohr, V. A. (2016). Nuclear DNA damage signaling to mitochondria in ageing. Nat. Rev. Mol. Cell Biol. 17, 308-321. doi: 10.1038/nrm.2016.14

Farris, W., Mansourian, S., Chang, Y., Lindsley, L., Eckman, E. A., Frosch, M. P., et al. (2003). Insulin-degrading enzyme regulates the levels of insulin, amyloid $\beta$-protein and the $\beta$-amyloid precursor protein intracellular domain in vivo. Proc. Natl. Acad. Sci. U S A 100, 4162-4167. doi: 10.1073/pnas.0230450100

Fealy, C. E., Nieuwoudt, S., Foucher, J. A., Scelsi, A. R., Malin, S. K., Pagadala, M., et al. (2018). Functional high-intensity exercise training ameliorates insulin resistance and cardiometabolic risk factors in type 2 diabetes. Exp. Physiol. 103, 985-994. doi: 10.1113/EP086844

Fewlass, D. C., Noboa, K., Pi-Sunyer, F. X., Johnston, J. M., Yan, S. D., and Tezapsidis, N. (2004). Obesity-related leptin regulates Alzheimer's A $\beta$. FASEB J. 18, 1870-1878. doi: 10.1096/fj.04-2572com

Filippi, B. M., Abraham, M. A., Silva, P. N., Rasti, M., LaPierre, M. P., Bauer, P. V., et al. (2017). Dynamin-related protein 1-dependent mitochondrial fission changes in the dorsal vagal complex regulate insulin action. Cell Rep. 18, 2301-2309. doi: 10.1016/j.celrep.2017.02.035

Freude, S., Plum, L., Schnitker, J., Leeser, U., Udelhoven, M., Krone, W., et al. (2005). Peripheral hyperinsulinemia promotes tau phosphorylation in vivo. Diabetes 54, 3343-3348. doi: 10.2337/diabetes.54.12.3343

Gaiteri, C., Mostafavi, S., Honey, C. J., De Jager, P. L., and Bennett, D. A. (2016). Genetic variants in Alzheimer disease-molecular and brain network approaches. Nat. Rev. Neurol. 12, 413-427. doi: 10.1038/nrneurol. 2016.84

Gao, R., Duff, W., Chizen, D., Zello, G. A., and Chilibeck, P. D. (2019). The effect of a low glycemic index pulse-based diet on insulin sensitivity, insulin resistance, bone resorption and cardiovascular risk factors during bed rest. Nutrients 11:2012. doi: 10.3390/nu11092012

Gasparini, L., Gouras, G. K., Wang, R., Gross, R. S., Beal, M. F., Greengard, P., et al. (2001). Stimulation of $\beta$-amyloid precursor protein trafficking by insulin reduces intraneuronal $\beta$-amyloid and requires mitogen-activated protein kinase signaling. J. Neurosci. 21, 2561-2570. doi: 10.1523/JNEUROSCI.21-0802561.2001

Ghavami, S., Shojaei, S., Yeganeh, B., Ande, S. R., Jangamreddy, J. R., Mehrpour, M., et al. (2014). Autophagy and apoptosis dysfunction in neurodegenerative disorders. Prog. Neurobiol. 112, 24-49. doi: 10.1016/j. pneurobio.2013.10.004

Gomes, A. P., Duarte, F. V., Nunes, P., Hubbard, B. P., Teodoro, J. S., Varela, A. T., et al. (2012). Berberine protects against high fat diet-induced dysfunction in muscle mitochondria by inducing SIRT1-dependent mitochondrial biogenesis. Biochim. Biophys. Acta 1822, 185-195. doi: 10.1016/j.bbadis.2011. 10.008

Gomez-Crisostomo, N. P., Lopez-Marure, R., Zapata, E., Zazueta, C., and Martinez-Abundis, E. (2013). Bax induces cytochrome c release by multiple mechanisms in mitochondria from MCF7 cells. J. Bioenerg. Biomembr. 45, 441-448. doi: 10.1007/s10863-013-9508-x

Gomez-Lazaro, M., Galindo, M. F., Melero-Fernandez de Mera, R. M., FernandezGomez, F. J., Concannon, C. G., Segura, M. F., et al. (2007). Reactive oxygen species and p38 mitogen-activated protein kinase activate Bax to induce mitochondrial cytochrome c release and apoptosis in response to malonate. Mol. Pharmacol. 71, 736-743. doi: 10.1124/mol.106.030718 
Gratuze, M., Julien, J., Petry, F. R., Morin, F., and Planel, E. (2017). Insulin deprivation induces PP2A inhibition and tau hyperphosphorylation in hTau mice, a model of Alzheimer's disease-like tau pathology. Sci. Rep. 7:46359. doi: $10.1038 /$ srep46359

Gregor, M. F., and Hotamisligil, G. S. (2011). Inflammatory mechanisms in obesity. Annu. Rev. Immunol. 29, 415-445. doi: 10.1146/annurev-immunol031210-101322

Guerriero, F., Sgarlata, C., Francis, M., Maurizi, N., Faragli, A., Perna, S., et al. (2017). Neuroinflammation, immune system and Alzheimer disease: searching for the missing link. Aging Clin. Exp. Res. 29, 821-831. doi: 10.1007/s40520016-0637-z

Guo, R., Liu, B., Zhou, S., Zhang, B., and Xu, Y. (2013). The protective effect of fasudil on the structure and function of cardiac mitochondria from rats with type 2 diabetes induced by streptozotocin with a high-fat diet is mediated by the attenuation of oxidative stress. Biomed Res. Int. 2013:430791. doi: 10.1155/2013/430791

Gupta, S., Knight, A. G., Gupta, S., Keller, J. N., and Bruce-Keller, A. J. (2012). Saturated long-chain fatty acids activate inflammatory signaling in astrocytes. J. Neurochem. 120, 1060-1071. doi: 10.1111/j.1471-4159.2012.07660.x

Hagiwara, S., Gohda, T., Tanimoto, M., Ito, T., Murakoshi, M., Ohara, I., et al. (2009). Effects of pyridoxamine (K-163) on glucose intolerance and obesity in high-fat diet C57BL/6J mice. Metabolism 58, 934-945. doi: 10.1016/j.metabol. 2009.02.033

Halagappa, V. K., Guo, Z., Pearson, M., Matsuoka, Y., Cutler, R. G., Laferla, F. M., et al. (2007). Intermittent fasting and caloric restriction ameliorate age-related behavioral deficits in the triple-transgenic mouse model of Alzheimer's disease. Neurobiol. Dis. 26, 212-220. doi: 10.1016/j.nbd.2006.12.019

Hall, J. A., Dominy, J. E., Lee, Y., and Puigserver, P. (2013). The sirtuin family's role in aging and age-associated pathologies. J. Clin. Invest. 123, 973-979. doi: 10.1172/JCI64094

Hara, Y., Yuk, F., Puri, R., Janssen, W. G., Rapp, P. R., and Morrison, J. H. (2014). Presynaptic mitochondrial morphology in monkey prefrontal cortex correlates with working memory and is improved with estrogen treatment. Proc. Natl. Acad. Sci. U S A 111, 486-491. doi: 10.1073/pnas.1311310110

Harcourt, B. E., Sourris, K. C., Coughlan, M. T., Walker, K. Z., Dougherty, S. L., Andrikopoulos, S., et al. (2011). Targeted reduction of advanced glycation improves renal function in obesity. Kidney Int. 80, 190-198. doi: 10.1038/ki. 2011.57

Hayden, M. R. (2019). Type 2 diabetes mellitus increases the risk of late-onset Alzheimer's disease: ultrastructural remodeling of the neurovascular unit and diabetic gliopathy. Brain Sci. 9:262. doi: 10.3390/brainsci9100262

Hersom, M., Helms, H. C., Schmalz, C., Pedersen, T. A., Buckley, S. T., and Brodin, B. (2018). The insulin receptor is expressed and functional in cultured blood-brain barrier endothelial cells but does not mediate insulin entry from blood to brain. Am. J. Physiol. Endocrinol. Metab. 315, E531-E542. doi: 10.1152/ajpendo.00350.2016

Ho, L., Qin, W., Pompl, P. N., Xiang, Z., Wang, J., Zhao, Z., et al. (2004). Dietinduced insulin resistance promotes amyloidosis in a transgenic mouse model of Alzheimer's disease. FASEB J. 18, 902-904. doi: 10.1096/fj.03-0978fje

Hoeks, J., and Schrauwen, P. (2012). Muscle mitochondria and insulin resistance: a human perspective. Trends Endocrinol. Metab. 23, 444-450. doi: 10.1016/j.tem. 2012.05.007

Hohman, T. J., and Kaczorowski, C. C. (2020). Modifiable lifestyle factors in Alzheimer disease: an opportunity to transform the therapeutic landscape through transdisciplinary collaboration. JAMA Neurol. [Epub ahead of print]. doi: 10.1001/jamaneurol.2020.1114

Hong, S., Dissing-Olesen, L., and Stevens, B. (2016). New insights on the role of microglia in synaptic pruning in health and disease. Curr. Opin. Neurobiol. 36, 128-134. doi: 10.1016/j.conb.2015.12.004

Hu, J. F., Niu, F., Ning, N., Duan, W. Z., Chu, S. F., Xue, W., et al. (2012). Activation of ERK1/2-CREB pathway during potentiating synaptic transmission of (-)clausenamide in rat dentate gyrus. J. Asian Nat. Prod. Res. 14, 256-262. doi: 10.1080/10286020.2011.650885

Huang, C. C., You, J. L., Lee, C. C., and Hsu, K. S. (2003). Insulin induces a novel form of postsynaptic mossy fiber long-term depression in the hippocampus. Mol. Cell. Neurosci. 24, 831-841. doi: 10.1016/S1044-7431(03)00238-0

Hunnicut, J., Liu, Y., Richardson, A., and Salmon, A. B. (2015). MsrA overexpression targeted to the mitochondria, but not cytosol, preserves insulin sensitivity in diet-induced obese mice. PLoS One 10:e139844. doi: 10.1371/journal.pone.0139844

Jack, C. R., Jr. (2020). Alzheimer disease, biomarkers and clinical symptoms-quo vadis?-Reply. JAMA Neurol. 77:394. doi: 10.1001/jamaneurol. 2019.4962

Ji, J., Qin, Y., Ren, J., Lu, C., Wang, R., Dai, X., et al. (2015). Mitochondria-related miR-141-3p contributes to mitochondrial dysfunction in HFD-induced obesity by inhibiting PTEN. Sci. Rep. 5:16262. doi: 10.1038/srep 16262

Jolivalt, C. G., Lee, C. A., Beiswenger, K. K., Smith, J. L., Orlov, M., Torrance, M. A., et al. (2008). Defective insulin signaling pathway and increased glycogen synthase kinase- 3 activity in the brain of diabetic mice: parallels with Alzheimer's disease and correction by insulin. J. Neurosci. Res. 86, 3265-3274. doi: $10.1002 /$ jnr.21787

Jones, K. T., Shelton, R. C., Wan, J., and Li, L. (2016). Impact of acute psychological stress on cardiovascular risk factors in face of insulin resistance. Stress 19, 585-592. doi: 10.1080/10253890.2016.1231804

Julien, C., Tremblay, C., Phivilay, A., Berthiaume, L., Emond, V., Julien, P., et al. (2010). High-fat diet aggravates amyloid- $\beta$ and tau pathologies in the $3 x \mathrm{Tg}-\mathrm{AD}$ mouse model. Neurobiol. Aging 31, 1516-1531. doi: 10.1016/j.neurobiolaging. 2008.08.022

Kalinovich, A. V., Mattsson, C. L., Youssef, M. R., Petrovic, N., Ost, M., Skulachev, V. P., et al. (2016). Mitochondria-targeted dodecyltriphenylphosphonium (C12TPP) combats high-fat-diet-induced obesity in mice. Int. J. Obes. 40, 1864-1874. doi: 10.1038/ijo.2016.146

Kalousova, M., Zima, T., Tesar, V., Dusilova-Sulkova, S., and Skrha, J. (2005). Advanced glycoxidation end products in chronic diseases-clinical chemistry and genetic background. Mutat. Res. 579, 37-46. doi: 10.1016/j.mrfmmm.2005. 03.024

Karmi, A., Iozzo, P., Viljanen, A., Hirvonen, J., Fielding, B. A., Virtanen, K., et al. (2010). Increased brain fatty acid uptake in metabolic syndrome. Diabetes 59 , 2171-2177. doi: 10.2337/db09-0138

Katiyar, S. K., and Meeran, S. M. (2007). Obesity increases the risk of UV radiationinduced oxidative stress and activation of MAPK and NF- $\mathrm{BB}$ signaling. Free Radic. Biol. Med. 42, 299-310. doi: 10.1016/j.freeradbiomed.2006.10.049

Kelleher, I., Garwood, C., Hanger, D. P., Anderton, B. H., and Noble, W. (2007). Kinase activities increase during the development of tauopathy in htau mice. J. Neurochem. 103, 2256-2267. doi: 10.1111/j.1471-4159.2007.04930.x

Kim, S. H., and Reaven, G. M. (2008). Insulin resistance and hyperinsulinemia: you can't have one without the other. Diabetes Care 31, 1433-1438. doi: $10.2337 / \mathrm{dc} 08-0045$

Knott, A. B., and Bossy-Wetzel, E. (2008). Impairing the mitochondrial fission and fusion balance: a new mechanism of neurodegeneration. Ann. N Y Acad. Sci. 1147, 283-292. doi: 10.1196/annals.1427.030

Koliaki, C., and Roden, M. (2016). Alterations of mitochondrial function and insulin sensitivity in human obesity and diabetes mellitus. Ann. Rev. Nutr. 36, 337-367. doi: 10.1146/annurev-nutr-071715-050656

Kuehn, B. M. (2020). In Alzheimer research, glucose metabolism moves to center stage. JAMA 323, 297-299. doi: 10.1001/jama.2019.20939

Kuwabara, T., Kagalwala, M. N., Onuma, Y., Ito, Y., Warashina, M., Terashima, K., et al. (2011). Insulin biosynthesis in neuronal progenitors derived from adult hippocampus and the olfactory bulb. EMBO Mol. Med. 3, 742-754. doi: 10.1002/emmm.201100177

Leboucher, A., Laurent, C., Fernandez-Gomez, F. J., Burnouf, S., Troquier, L., Eddarkaoui, S., et al. (2013). Detrimental effects of diet-induced obesity on tau pathology are independent of insulin resistance in tau transgenic mice. Diabetes 62, 1681-1688. doi: 10.2337/db12-0866

Lee, A., Hirabayashi, Y., Kwon, S. K., Lewis, T. L., Jr. and Polleux, F. (2018). Emerging roles of mitochondria in synaptic transmission and neurodegeneration. Curr. Opin. Physiol. 3, 82-93. doi: 10.1016/j.cophys.2018. 03.009

Lee, S. H., Zabolotny, J. M., Huang, H., Lee, H., and Kim, Y. B. (2016). Insulin in the nervous system and the mind: functions in metabolism, memory and mood. Mol. Metab. 5, 589-601. doi: 10.1016/j.molmet.2016.06.011

Leuner, B., Max, M., Thamm, K., Kausler, C., Yakobus, Y., Bierhaus, A., et al. (2012). RAGE influences obesity in mice. Effects of the presence of RAGE on weight gain, AGE accumulation and insulin levels in mice on a high fat diet. Z. Gerontol. Geriatr. 45, 102-108. doi: 10.1007/s00391-0110279-x 
Levin-Allerhand, J. A., Lominska, C. E., and Smith, J. D. (2002). Increased amyloid-levels in APPSWE transgenic mice treated chronically with a physiological high-fat high-cholesterol diet. J. Nutr. Health Aging 6, 315-319.

Li, S. Y., Liu, Y., Sigmon, V. K., McCort, A., and Ren, J. (2005). High-fat diet enhances visceral advanced glycation end products, nuclear O-Glc-Nac modification, p38 mitogen-activated protein kinase activation and apoptosis. Diabetes Obes. Metab. 7, 448-454. doi: 10.1111/j.1463-1326.2004.00387.x

Li, X. H., Lv, B. L., Xie, J. Z., Liu, J., Zhou, X. W., and Wang, J. Z. (2012). AGEs induce Alzheimer-like tau pathology and memory deficit via RAGE-mediated GSK-3 activation. Neurobiol. Aging 33, 1400-1410. doi: 10.1016/j.neurobiolaging.2011.02.003

Li, M. Z., Zheng, L. J., Shen, J., Li, X. Y., Zhang, Q., Bai, X., et al. (2018). SIRT1 facilitates amyloid $\beta$ peptide degradation by upregulating lysosome number in primary astrocytes. Neural Regen. Res. 13, 2005-2013. doi: $10.4103 / 1673-5374.239449$

Lin, C. H., Tomioka, M., Pereira, S., Sellings, L., Iino, Y., and van der Kooy, D. (2010). Insulin signaling plays a dual role in Caenorhabditis elegans memory acquisition and memory retrieval. J. Neurosci. 30, 8001-8011. doi: 10.1523/JNEUROSCI.4636-09.2010

Liu, X., and Hajnoczky, G. (2011). Altered fusion dynamics underlie unique morphological changes in mitochondria during hypoxia-reoxygenation stress. Cell Death Differ. 18, 1561-1572. doi: 10.1038/cdd.2011.13

Marks, J. L., Porte, D., Jr. and Baskin, D. G. (1991). Localization of type I insulin-like growth factor receptor messenger RNA in the adult rat brain by in situ hybridization. Mol. Endocrinol. 5, 1158-1168. doi: 10.1210/mend5-8-1158

Martins, I. J. (2013). Increased risk for obesity and diabetes with neurodegeneration in developing countries. J. Mol. Genet. Med. S1:001. doi: 10.4172/1747-0862.S1-001

Martins, I. J. (2016a). Food quality induces a miscible disease with relevance to Alzheimer's disease and neurological diseases. J. Food Res. 5:6. doi: 10.5539/jfr. v5n6p45

Martins, I. J. (2016b). Anti-aging genes improve appetite regulation and reverse cell senescence and apoptosis in global populations. Advan. Aging Res. 5, 9-26. doi: 10.4236/aar.2016.51002

Martins, I. J. (2017a). Nutrition therapy regulates caffeine metabolism with relevance to NAFLD and induction of Type 3 diabetes. J. Diabetes Metab. Disord. 4, 1-9. doi: 10.24966/DMD-201X/100019

Martins, I. J. (2017b). Single gene inactivation with implications to diabetes and multiple organ dysfunction syndrome. J. Clin. Epigenet. 3:24. doi: $10.21767 / 2472-1158.100058$

Martins, I. J. (2018). Sirtuin 1, a diagnostic protein marker and its relevance to chronic disease and therapeutic drug interventions. EC Pharmacol. Toxicol. 6.4, 209-215.

Martins, I. J. (2012). Sirtuin-1 mediates the obesity induced risk of common degenerative diseases: Alzheimer's disease, coronary artery disease and Type 2 diabetes. Spec. Issue Obes. Health 4, 1448-1456. doi: 10.4236/health.2012. 412A209

Martins, I. J., Wilson, A. C., Florence, W. L., Laws, S. M., Fuller, S. J., and Martins, R. N. (2015). Unhealthy nutrigenomic diets accelerate NAFLD and adiposity in global communities. Mol. Gen. Med. 9:162. doi: 10.4172/1747-0862. 1000162

Mattson, M. P., Gleichmann, M., and Cheng, A. (2008). Mitochondria in neuroplasticity and neurological disorders. Neuron 60, 748-766. doi: 10.1016/j. neuron.2008.10.010

Mitchell, R. W., and Hatch, G. M. (2011). Fatty acid transport into the brain: of fatty acid fables and lipid tails. Prostaglandins Leukot. Essent. Fatty Acids 85, 293-302. doi: 10.1016/j.plefa.2011.04.007

Morley, J. E., Farr, S. A., Sell, R. L., Hileman, S. M., and Banks, W. A. (2011). Nitric oxide is a central component in neuropeptide regulation of appetite. Peptides 32, 776-780. doi: 10.1016/j.peptides.2010.12.015

Morrow, R. M., Picard, M., Derbeneva, O., Leipzig, J., McManus, M. J., Gouspillou, G., et al. (2017). Mitochondrial energy deficiency leads to hyperproliferation of skeletal muscle mitochondria and enhanced insulin sensitivity. Proc. Natl. Acad. Sci. U S A 114, 2705-2710. doi: 10.1073/pnas. 1700997114

Mourelatou, R., Kostopoulou, E., Rojas-Gil, A. P., Kehagias, I., Linos, D., Kalfarentzos, F. E., et al. (2019). Decreased adipocyte glucose transporter
4 (GLUT4) and aquaglyceroporin-7 (AQP7) in adults with morbid obesity: possible early markers of metabolic dysfunction. Hormones 18, 297-306. doi: 10.1007/s42000-019-00130-8

Mouton, P. R., Chachich, M. E., Quigley, C., Spangler, E., and Ingram, D. K. (2009). Caloric restriction attenuates amyloid deposition in middle-aged dtg APP/PS1 mice. Neurosci. Lett. 464, 184-187. doi: 10.1016/j.neulet.2009.08.038

Nagamatsu, S., Sawa, H., Inoue, N., Nakamichi, Y., Takeshima, H., and Hoshino, T. (1994). Gene expression of GLUT3 glucose transporter regulated by glucose in vivo in mouse brain and in vitro in neuronal cell cultures from rat embryos. Biochem. J. 300, 125-131. doi: 10.1042/bj3000125

Nampoothiri, M., Ramalingayya, G. V., Kutty, N. G., Krishnadas, N., and Rao, C. M. (2017). Insulin combined with glucose improves spatial learning and memory in aluminum chloride-induced dementia in rats. J. Environ. Pathol. Toxicol. Oncol. 36, 159-169. doi: 10.1615/JEnvironPatholToxicolOncol. 2017020185

Nelson, T. J., Sun, M. K., Hongpaisan, J., and Alkon, D. L. (2008). Insulin, PKC signaling pathways and synaptic remodeling during memory storage and neuronal repair. Eur. J. Pharmacol. 585, 76-87. doi: 10.1016/j.ejphar.2008. 01.051

Nifli, A. P. (2018). Appetite, metabolism and hormonal regulation in normal ageing and dementia. Diseases 6:66. doi: 10.3390/diseases6030066

Nisoli, E., Clementi, E., Paolucci, C., Cozzi, V., Tonello, C., Sciorati, C., et al. (2003). Mitochondrial biogenesis in mammals: the role of endogenous nitric oxide. Science 299, 896-899. doi: 10.1126/science. 1079368

Nistico, R., Cavallucci, V., Piccinin, S., Macri, S., Pignatelli, M., Mehdawy, B., et al. (2012). Insulin receptor beta-subunit haploinsufficiency impairs hippocampal late-phase LTP and recognition memory. Neuromolecular Med. 14, 262-269. doi: 10.1007/s12017-012-8184-z

Nuzzo, D., Picone, P., Baldassano, S., Caruana, L., Messina, E., Marino Gammazza, A., et al. (2015). Insulin resistance as common molecular denominator linking obesity to Alzheimer's disease. Curr. Alzheimer Res. 12, 723-735. doi: 10.2174/1567205012666150710115506

Ow, S. Y., and Dunstan, D. E. (2014). A brief overview of amyloids and Alzheimer's disease. Protein Sci. 23, 1315-1331. doi: 10.1002/pro.2524

Pardo, P. S., and Boriek, A. M. (2020). SIRT1 regulation in ageing and obesity. Mech. Ageing Dev. 188:111249. doi: 10.1016/j.mad.2020.111249

Patel, N. V., Gordon, M. N., Connor, K. E., Good, R. A., Engelman, R. W., Mason, J., et al. (2005). Caloric restriction attenuates Abeta-deposition in Alzheimer transgenic models. Neurobiol. Aging 26, 995-1000. doi: 10.1016/j. neurobiolaging.2004.09.014

Pearson-Leary, J., Jahagirdar, V., Sage, J., and McNay, E. C. (2018). Insulin modulates hippocampally-mediated spatial working memory via glucose transporter-4. Behav. Brain Res. 338, 32-39. doi: 10.1016/j.bbr.2017.09.033

Pedrini, S., Thomas, C., Brautigam, H., Schmeidler, J., Ho, L., Fraser, P., et al. (2009). Dietary composition modulates brain mass and solubilizable $A \beta$ levels in a mouse model of aggressive Alzheimer's amyloid pathology. Mol. Neurodegener. 4:40. doi: 10.1186/1750-1326-4-40

Perfettini, J. L., Roumier, T., and Kroemer, G. (2005). Mitochondrial fusion and fission in the control of apoptosis. Trends Cell Biol. 15, 179-183. doi: 10.1016/j. tcb.2005.02.005

Pfanner, N., Warscheid, B., and Wiedemann, N. (2019). Mitochondrial proteins: from biogenesis to functional networks. Nat. Rev. Mol. Cell Biol. 20, 267-284. doi: 10.1038/s41580-018-0092-0

Pintana, H., Apaijai, N., Chattipakorn, N., and Chattipakorn, S. C. (2013). DPP4 inhibitors improve cognition and brain mitochondrial function of insulinresistant rats. J. Endocrinol. 218, 1-11. doi: 10.1530/JOE-12-0521

Pipatpiboon, N., Pintana, H., Pratchayasakul, W., Chattipakorn, N., and Chattipakorn, S. C. (2013). DPP4-inhibitor improves neuronal insulin receptor function, brain mitochondrial function and cognitive function in rats with insulin resistance induced by high-fat diet consumption. Eur. J. Neurosci. 37, 839-849. doi: 10.1111/ejn.12088

Pitt, J., Wilcox, K. C., Tortelli, V., Diniz, L. P., Oliveira, M. S., Dobbins, C., et al. (2017). Neuroprotective astrocyte-derived insulin/insulin-like growth factor 1 stimulates endocytic processing and extracellular release of neuron-bound A $\beta$ oligomers. Mol. Biol. Cell 28, 2623-2636. doi: 10.1091/mbc.E17-06-0416

Platt, T. L., Beckett, T. L., Kohler, K., Niedowicz, D. M., and Murphy, M. P. (2016). Obesity, diabetes and leptin resistance promote tau pathology in a mouse model of disease. Neuroscience 315, 162-174. doi: 10.1016/j.neuroscience.2015.12.011 
Plum, L., Schubert, M., and Bruning, J. C. (2005). The role of insulin receptor signaling in the brain. Trends Endocrinol. Metab. 16, 59-65. doi: 10.1016/j.tem. 2005.01.008

Pomytkin, I., Costa-Nunes, J. P., Kasatkin, V., Veniaminova, E., Demchenko, A., Lyundup, A., et al. (2018). Insulin receptor in the brain: mechanisms of activation and the role in the CNS pathology and treatment. CNS Neurosci. Ther. 24, 763-774. doi: 10.1111/cns.12866

Porter, D., Faivre, E., Flatt, P. R., Holscher, C., and Gault, V. A. (2012). Actions of incretin metabolites on locomotor activity, cognitive function and in vivo hippocampal synaptic plasticity in high fat fed mice. Peptides 35, 1-8. doi: 10.1016/j.peptides.2012.03.014

Porter, W. D., Flatt, P. R., Holscher, C., and Gault, V. A. (2013). Liraglutide improves hippocampal synaptic plasticity associated with increased expression of Mash1 in ob/ob mice. Int. J. Obes. 37, 678-684. doi: 10.1038/ijo.2012.91

Pugazhenthi, S., Qin, L., and Reddy, P. H. (2017). Common neurodegenerative pathways in obesity, diabetes and Alzheimer's disease. Biochim. Biophys. Acta Mol. Basis Dis. 1863, 1037-1045. doi: 10.1016/j.bbadis.2016.04.017

Puig, K. L., Floden, A. M., Adhikari, R., Golovko, M. Y., and Combs, C. K. (2012). Amyloid precursor protein and proinflammatory changes are regulated in brain and adipose tissue in a murine model of high fat diet-induced obesity. PLoS One 7:e30378. doi: 10.1371/journal.pone.0030378

Qiu, W. Q., and Folstein, M. F. (2006). Insulin, insulin-degrading enzyme and amyloid- $\beta$ peptide in Alzheimer's disease: review and hypothesis. Neurobiol. Aging 27, 190-198. doi: 10.1016/j.neurobiolaging.2005.01.004

Rabbani, N., Xue, M., and Thornalley, P. J. (2016). Dicarbonyls and glyoxalase in disease mechanisms and clinical therapeutics. GlycoconJ. J. 33, 513-525. doi: 10.1007/s10719-016-9705-Z

Raefsky, S. M., and Mattson, M. P. (2017). Adaptive responses of neuronal mitochondria to bioenergetic challenges: roles in neuroplasticity and disease resistance. Free Radic. Biol. Med. 102, 203-216. doi: 10.1016/j.freeradbiomed. 2016.11.045

Ramasamy, R., Vannucci, S. J., Yan, S. S., Herold, K., Yan, S. F., and Schmidt, A. M. (2005). Advanced glycation end products and RAGE: a common thread in aging, diabetes, neurodegeneration and inflammation. Glycobiology 15, 16R-28R. doi: 10.1093/glycob/cwi053

Raza, H., John, A., and Howarth, F. C. (2015). Increased oxidative stress and mitochondrial dysfunction in zucker diabetic rat liver and brain. Cell. Physiol. Biochem. 35, 1241-1251. doi: 10.1159/000373947

Reger, M. A., Watson, G. S., Frey, W. H., 2nd, Baker, L. D., Cholerton, B., Keeling, M. L., et al. (2006). Effects of intranasal insulin on cognition in memory-impaired older adults: modulation by APOE genotype. Neurobiol. Aging 27, 451-458. doi: 10.1016/j.neurobiolaging.2005.03.016

Reisberg, B., Ferris, S. H., de Leon, M. J., Kluger, A., Franssen, E., Borenstein, J., et al. (1989). The stage specific temporal course of Alzheimer's disease: functional and behavioral concomitants based upon cross-sectional and longitudinal observation. Prog. Clin. Biol. Res. 317, 23-41.

Ren, J., Sun, M., Zhou, H., Ajoolabady, A., Zhou, Y., Tao, J., et al. (2020). FUNDC1 interacts with FBXL2 to govern mitochondrial integrity and cardiac function through an IP3R3-dependent manner in obesity. Sci. Adv. 6:eabc8561. doi: 10.1126/sciadv.abc8561

Roth, R. J., Le, A. M., Zhang, L., Kahn, M., Samuel, V. T., Shulman, G. I., et al. (2009). MAPK phosphatase-1 facilitates the loss of oxidative myofibers associated with obesity in mice. J. Clin. Invest. 119, 3817-3829. doi: 10.1172/JCI39054

Rus, A., Molina, F., Gasso, M., Camacho, M. V., Peinado, M. A., and del Moral, M. L. (2016). Nitric oxide, inflammation, lipid profile and cortisol in normal- and overweight women with fibromyalgia. Biol. Res. Nurs. 18, 138-146. doi: 10.1177/1099800415591035

Sa-Nguanmoo, P., Tanajak, P., Kerdphoo, S., Jaiwongkam, T., Pratchayasakul, W., Chattipakorn, N., et al. (2017). SGLT2-inhibitor and DPP-4 inhibitor improve brain function via attenuating mitochondrial dysfunction, insulin resistance, inflammation and apoptosis in HFD-induced obese rats. Toxicol. App. Pharmacol. 333, 43-50. doi: 10.1016/j.taap.2017.08.005

Sa-Nguanmoo, P., Tanajak, P., Kerdphoo, S., Satjaritanun, P., Wang, X., Liang, G., et al. (2016). FGF21 improves cognition by restored synaptic plasticity, dendritic spine density, brain mitochondrial function and cell apoptosis in obese-insulin resistant male rats. Horm. Behav. 85, 86-95. doi: 10.1016/j.yhbeh. 2016.08.006
Saltiel, A. R., and Olefsky, J. M. (2017). Inflammatory mechanisms linking obesity and metabolic disease. J. Clin. Invest. 127, 1-4. doi: 10.1172/JCI92035

Selles, M. C., Fortuna, J. T. S., Zappa-Villar, M. F., de Faria, Y. P. R., Souza, A. S., Suemoto, C. K., et al. (2020). Adenovirus-mediated transduction of insulin-like growth factor 1 protects hippocampal neurons from the toxicity of $\mathrm{A} \beta$ oligomers and prevents memory loss in an Alzheimer mouse model. Mol. Neurobiol. 57, 1473-1483. doi: 10.1007/s12035-019-01827-y

Shie, F. S., Shiao, Y. J., Yeh, C. W., Lin, C. H., Tzeng, T. T., Hsu, H. C., et al. (2015). Obesity and hepatic steatosis are associated with elevated serum amyloid $\beta$ in metabolically stressed APPswe/PS1dE9 mice. PLoS One 10:e134531. doi: 10.1371/journal.pone.0134531

Small, G. W., Ercoli, L. M., Silverman, D. H., Huang, S. C., Komo, S., Bookheimer, S. Y., et al. (2000). Cerebral metabolic and cognitive decline in persons at genetic risk for Alzheimer's disease. Proc. Natl. Acad. Sci. U S A 97, 6037-6042. doi: 10.1073/pnas.090106797

Spellicy, C. J., Norris, J., Bend, R., Bupp, C., Mester, P., Reynolds, T., et al. (2018). Key apoptotic genes APAF1 and CASP9 implicated in recurrent folate-resistant neural tube defects. Eur. J. Hum. Genet. 26, 420-427. doi: 10.1038/s41431-0170025-y

Sripetchwandee, J., Pipatpiboon, N., Pratchayasakul, W., Chattipakorn, N., and Chattipakorn, S. C. (2014). DPP-4 inhibitor and PPAR $\gamma$ agonist restore the loss of CA1 dendritic spines in obese insulin-resistant rats. Arch. Med. Res. 45, 547-552. doi: 10.1016/j.arcmed.2014.09.002

Steen, E., Terry, B. M., Rivera, E. J., Cannon, J. L., Neely, T. R., Tavares, R., et al. (2005). Impaired insulin and insulin-like growth factor expression and signaling mechanisms in Alzheimer's disease-is this type 3 diabetes? J. Alzheimers Dis. 7, 63-80. doi: 10.3233/jad-2005-7107

Studzinski, C. M., Li, F., Bruce-Keller, A. J., Fernandez-Kim, S. O., Zhang, L., Weidner, A. M., et al. (2009). Effects of short-term Western diet on cerebral oxidative stress and diabetes related factors in APP $\times$ PS1 knock-in mice. J. Neurochem. 108, 860-866. doi: 10.1111/j.1471-4159.2008.05798.x

Sun, H. L., Chen, S. H., Yu, Z. Y., Cheng, Y., Tian, D. Y., Fan, D. Y., et al. (2020). Blood cell-produced amyloid- $\beta$ induces cerebral Alzheimer-type pathologies and behavioral deficits. Mol. Psychiatry doi: 10.1038/s41380-020-0842-1

Swerdlow, R. H. (2020). Mitochondria in Alzheimer brains: a PET project shows complex changes. Neurology 94, 646-647. doi: 10.1212/WNL. 0000000000009236

Takuma, K., Fang, F., Zhang, W., Yan, S., Fukuzaki, E., Du, H., et al. (2009). RAGE-mediated signaling contributes to intraneuronal transport of amyloid- $\beta$ and neuronal dysfunction. Proc. Natl. Acad. Sci. U S A 106, 20021-20026. doi: 10.1073/pnas.0905686106

Talbot, K., Wang, H. Y., Kazi, H., Han, L. Y., Bakshi, K. P., Stucky, A., et al. (2012). Demonstrated brain insulin resistance in Alzheimer's disease patients is associated with IGF-1 resistance, IRS-1 dysregulation and cognitive decline. J. Clin. Invest. 122, 1316-1338. doi: 10.1172/JCI59903

Tezapsidis, N., Smith, M. A., and Ashford, J. W. (2009). Central obesity and increased risk of dementia more than three decades later. Neurology 72, 1030-1031. doi: 10.1212/01.wnl.0000343499.72241.ea

Thoudam, T., Ha, C. M., Leem, J., Chanda, D., Park, J. S., Kim, H. J., et al. (2019). PDK4 augments ER-mitochondria contact to dampen skeletal muscle insulin signaling during obesity. Diabetes 68, 571-586. doi: 10.2337/ db18-0363

Tomino, Y., Hagiwara, S., and Gohda, T. (2011). AGE-RAGE interaction and oxidative stress in obesity-related renal dysfunction. Kidney Int. 80, 133-135. doi: $10.1038 / \mathrm{ki} .2011 .86$

Torralba, D., Baixauli, F., and Sanchez-Madrid, F. (2016). Mitochondria know no boundaries: mechanisms and functions of intercellular mitochondrial transfer. Front. Cell Dev. Biol. 4:107. doi: 10.3389/fcell.2016.00107

Tripathy, D., Mohanty, P., Dhindsa, S., Syed, T., Ghanim, H., Aljada, A., et al. (2003). Elevation of free fatty acids induces inflammation and impairs vascular reactivity in healthy subjects. Diabetes 52, 2882-2887. doi: 10.2337/diabetes.52. 12.2882

Tse, J. K. Y. (2017). Gut microbiota, nitric oxide and microglia as prerequisites for neurodegenerative disorders. ACS Chem. Neurosci. 8, 1438-1447. doi: 10.1021/acschemneuro.7b00176

Uranga, R. M., and Keller, J. N. (2019). The complex interactions between obesity, metabolism and the brain. Front. Neurosci. 13:513. doi: 10.3389/fnins.2019. 00513 
Van der Auwera, I., Wera, S., Van Leuven, F., and Henderson, S. T. (2005). A ketogenic diet reduces amyloid $\beta 40$ and 42 in a mouse model of Alzheimer's disease. Nutr. Metab. 2:28. doi: 10.1186/1743-7075-2-28

Vernochet, C., and Kahn, C. R. (2012). Mitochondria, obesity and aging. Aging 4, 859-860. doi: 10.18632/aging.100518

Wang, L., Guo, L., Lu, L., Sun, H., Shao, M., Beck, S. J., et al. (2016). Synaptosomal mitochondrial dysfunction in $5 \times \mathrm{FAD}$ mouse model of Alzheimer's disease. PLoS One 11:e0150441. doi: 10.1371/journal.pone.0150441

Wang, J., Ho, L., Qin, W., Rocher, A. B., Seror, I., Humala, N., et al. (2005). Caloric restriction attenuates $\beta$-amyloid neuropathology in a mouse model of Alzheimer's disease. FASEB J. 19, 659-661. doi: 10.1096/fj.04-3182fje

Wang, D., Yan, J., Chen, J., Wu, W., Zhu, X., and Wang, Y. (2015). Naringin improves neuronal insulin signaling, brain mitochondrial function and cognitive function in high-fat diet-induced obese mice. Cell. Mol. Neurobiol. 35, 1061-1071. doi: 10.1007/s10571-015-0201-y

Wang, H., Zhao, Z., Liu, C., Guo, Z., Yuan, Y., Zhao, H., et al. (2018). Receptor for advanced glycation end-products (RAGE) blockade do damage to neuronal survival via disrupting wnt/beta-catenin signaling in spinal cord injury. Neurochem. Res. 43, 1405-1412. doi: 10.1007/s11064-018-2555-2

Watson, G. S., and Craft, S. (2004). Modulation of memory by insulin and glucose: neuropsychological observations in Alzheimer's disease. Eur. J. Pharmacol. 490, 97-113. doi: 10.1016/j.ejphar.2004.02.048

Whitmer, R. A., Gunderson, E. P., Quesenberry, C. P., Jr., Zhou, J., and Yaffe, K. (2007). Body mass index in midlife and risk of Alzheimer disease and vascular dementia. Curr. Alzheimer Res. 4, 103-109. doi: 10.2174/156720507780362047

World Health Organization. (2020). Obesity and Overweight. Available online at: https://www.who.int/dietphysicalactivity/media/en/gsfs_obesity.pdf

Wyss-Coray, T., and Mucke, L. (2002). Inflammation in neurodegenerative disease-a double-edged sword. Neuron 35, 419-432. doi: 10.1016/s08966273(02)00794-8
Yamagishi, S., and Matsui, T. (2010). Advanced glycation end products, oxidative stress and diabetic nephropathy. Oxid. Med. Cell. Longev. 3, 101-108. doi: 10.4161/oxim.3.2.11148

Yuan, Y., Cruzat, V. F., Newsholme, P., Cheng, J., Chen, Y., and Lu, Y. (2016). Regulation of SIRT1 in aging: roles in mitochondrial function and biogenesis. Mech. Ageing Dev. 155, 10-21. doi: 10.1016/j.mad.2016. 02.003

Zhang, W., Huang, Q., Zeng, Z., Wu, J., Zhang, Y., and Chen, Z. (2017). Sirt1 inhibits oxidative stress in vascular endothelial cells. Oxid. Med. Cell. Longev. 2017:7543973. doi: 10.1155/2017/7543973

Zhang, D., Liu, Z. X., Choi, C. S., Tian, L., Kibbey, R., Dong, J., et al. (2007). Mitochondrial dysfunction due to long-chain Acyl-CoA dehydrogenase deficiency causes hepatic steatosis and hepatic insulin resistance. Proc. Natl. Acad. Sci. U S A 104, 17075-17080. doi: 10.1073/pnas.0707060104

Zhang, X. S., Wu, Q., Wu, L. Y., Ye, Z. N., Jiang, T. W., Li, W., et al. (2016). Sirtuin 1 activation protects against early brain injury after experimental subarachnoid hemorrhage in rats. Cell Death Dis. 7:e2416. doi: 10.1038/cddis. 2016.292

Conflict of Interest: The authors declare that the research was conducted in the absence of any commercial or financial relationships that could be construed as a potential conflict of interest.

Copyright (C) 2020 Tabassum, Misrani and Yang. This is an open-access article distributed under the terms of the Creative Commons Attribution License (CC BY). The use, distribution or reproduction in other forums is permitted, provided the original author(s) and the copyright owner(s) are credited and that the original publication in this journal is cited, in accordance with accepted academic practice. No use, distribution or reproduction is permitted which does not comply with these terms. 